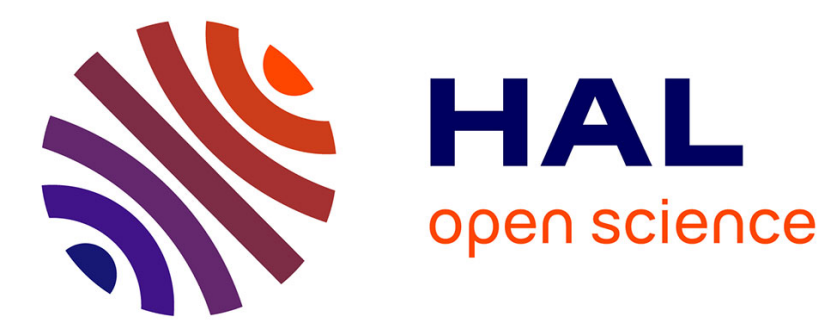

\title{
Performance Enhancement of a Vertical Tail Model with Sweeping Jets
}

Julien Dandois, Christophe Verbeke, Frédéric Ternoy

\section{To cite this version:}

Julien Dandois, Christophe Verbeke, Frédéric Ternoy. Performance Enhancement of a Vertical Tail Model with Sweeping Jets. 2019. hal-02382328

\section{HAL Id: hal-02382328 \\ https://hal.science/hal-02382328}

Preprint submitted on 27 Nov 2019

HAL is a multi-disciplinary open access archive for the deposit and dissemination of scientific research documents, whether they are published or not. The documents may come from teaching and research institutions in France or abroad, or from public or private research centers.
L'archive ouverte pluridisciplinaire HAL, est destinée au dépôt et à la diffusion de documents scientifiques de niveau recherche, publiés ou non, émanant des établissements d'enseignement et de recherche français ou étrangers, des laboratoires publics ou privés. 


\title{
Performance Enhancement of a Vertical Tail Model with Sweeping Jets
}

\author{
Julien Dandois ${ }^{1}$, \\ ONERA-Paris Saclay University, 92190 Meudon, France \\ Christophe Verbeke ${ }^{2}$ \\ Univ. Lille, CNRS, ONERA, Arts et Metiers ParisTech, Centrale Lille, \\ FRE 2017 - LMFL - Laboratory of Fluid Mechanics of Lille - Kampé de Feriet, \\ F-59000 Lille, France \\ and \\ Frédéric Ternoy ${ }^{3}$ \\ ONERA, 59045 Lille, France
}

Active flow control to delay the flow separation on the rudder of two different models has been investigated in the ONERA L1 wind tunnel. The first model was used as a simplified test case and consisted in a flat plate with a rudder. Different types of actuation were investigated: continuous/pulsed blowing through slots, continuous blowing through segmented slots and sweeping jets. The lift increments of these different types of actuation were compared not only in terms of mass flow rate but also in terms of momentum and power coefficients. Active flow control by sweeping jets was selected to be tested on the second model which is a scale 1:2 vertical tail model of a generic business jet. Side force increments up to $80 \%$ were achieved with a $2 \%$ value of $C_{\mu}$ coefficient. Side force increments of $50 \%$ were also reached with a lower $C_{\mu}$ value of $0.5 \%$. These side force increments could lead to a reduction of vertical tail plane wetted area and weight and consequently to a reduction of drag cruise and fuel consumption.

\footnotetext{
${ }^{1}$ Research Engineer, Department of Aerodynamics, Aeroelasticity and Acoustics; julien.dandois@onera.fr.

${ }^{2}$ Research Engineer, Department of Aerodynamics, Aeroelasticity and Acoustics.

${ }^{3}$ Head of Specific Devices \& Models Unit, Wind Tunnel Directorate.
} 


\section{Nomenclature}

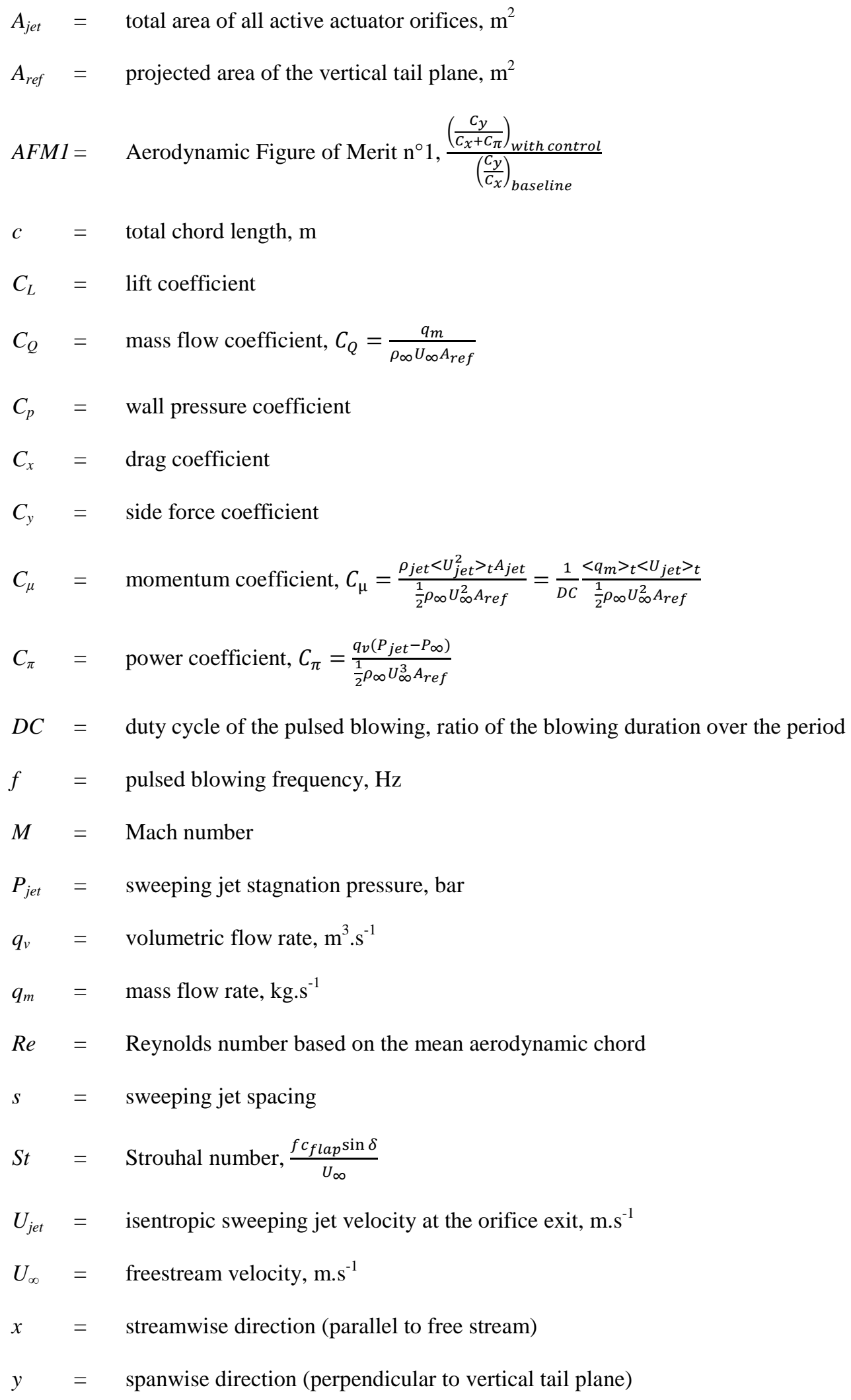




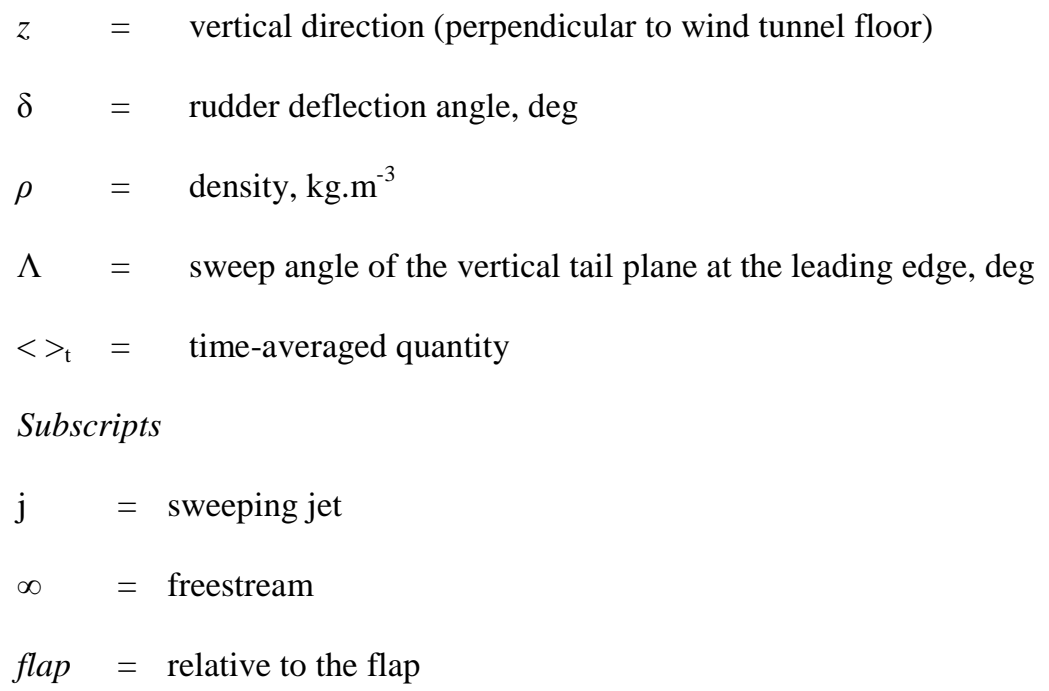

\section{Introduction}

1 HE vertical tail of multi-engine transport aircraft is typically sized to overcome an one-engine-inoperative event counterbalanced by the side force generated by the vertical tail plane (VTP). Since during take-off the aircraft velocity is low, the VTP area has to be oversized with respect to the requirements of stability during cruise flight which leads to additional drag, weight and finally increased fuel consumption. If one wants to decrease the VTP size, the side force loss due to the reduced area has to be compensated using active flow control (AFC) for example. Another possibility, which is purely mechanical, is to use for example double hinged rudder [1]. The side force is increased by $23 \%$ when the first part of the rudder is deflected at $25^{\circ}$ and the second part at $50^{\circ}$. Hence, it would be possible to keep a reduced area VTP during the cruise flight which constitutes the largest part of the mission profile of a transport aircraft and use AFC only during the rare event of an engine failure. AFC may be used to delay flow separation over highly deflected rudders and increase the side force that it generates. In a system integration study, Mooney et al. [2] concluded that despite an increased weight, specific fuel consumption (SFC) and maintenance costs, thanks to the reduced drag, the net result is still a benefit with 47 tons of fuel saved per aircraft per year.

Since 2010, a large number of the studies on the application of AFC on VTP have been performed in the framework of NASA Environmentally Responsible Aviation (ERA) project. Two types of actuation have been investigated: synthetic jets and sweeping jets. The main advantage of synthetic jets is that they only require an 
electrical supply. However, the main drawback is that their peak velocity or momentum is quite limited for the moment. On the contrary, sweeping jets [3]-[6] can reach high values of the momentum coefficient and they are simple and reliable because they have no moving parts. The main drawback is that they require air supply such as bleed air off an engine, an Auxiliary Power Unit (APU) or a compressor which is the reason why all the studies are focusing on the objective of decreasing the mass flow rate required to control the flow.

In order to prepare upcoming wind tunnel tests at high Reynolds number and the flight tests, AFC with sweeping jets was first studied on a two-dimensional NACA 0015 airfoil with a 30\% trailing edge flap by Pack Melton et al. [7]-[11]. A lift increment of 0.13 was obtained for a momentum coefficient $C_{\mu}$ equal to $1 \%$ and a rudder deflection $\delta$ equal to $20^{\circ}$. It was observed that sweeping jets located upstream of the flap shoulder were more effective than the ones located on the flap. The effect of the sweeping jets orifice dimensions was also investigated and the conclusion was that smaller orifices are more efficient in terms of mass flow rate but required larger power coefficient $C_{\pi}$. Three different sweeping jet geometries were also tested. The results showed that the actuator with the largest jet deflection angle was the most efficient at controlling the flow separation. The comparison between sweeping and non-sweeping jets showed that sweeping jets are more efficient in terms of mass flow rate and momentum coefficient because they create streamwise vortices which help reattaching the flow. AFC on a VTP with sweeping jets has been studied both experimentally [12]-[17] and numerically [18]-[21]. In summary, a side lift increment of $50 \%$ for $C_{\mu}=2 \%$ and a flap deflection of $30^{\circ}$ was obtained but a significant gain of $20 \%$ was already observed for a more limited $C_{\mu}$ value of $0.5 \%$ [13]. With passive flow control (vortex generators), the side lift increment was limited to only $10 \%$ [17]. Moreover, the velocity ratio between the actuator and the freestream velocity has to be larger than three to register a positive effect [13]. In addition, a larger actuator spacing led to a higher side lift increment for low $C_{\mu}$ values and the opposite for $C_{\mu} \geq 0.6 \%$. Concerning the effect of actuator position, it was observed that actuating only on the lower half of the model was more effective than on the upper half. Like Pack Melton et al., Seele et al. [13] noticed that smaller orifice areas enable to decrease the mass flow rate requirement but increase the power consumption. Contrary to Pack Melton et al., they observe that actuation on the rudder is more effective. Concerning the blowing orientation, a jet axis perpendicular to the rudder hinge is more effective [13]. The results of the flight tests are a side force increment of $14 \%$ for a rudder deflection of $30^{\circ}$ and the maximum mass flow rate from the APU. The comparison between the numerical simulations of Shmilovich et al. [19] and the 
wind tunnel tests has exhibited a good agreement. They have also shown that a hot jet temperature is beneficial from the mass flow rate point of view while keeping the momentum constant [21].

AFC on VTP with synthetic jets has also been studied both experimentally [22]-[24] and numerically [25]-[26]. A side force increment of $18 \%$ was obtained for $C_{\mu}=0.7 \%$ and a non-dimensionalized rudder deflection angle $\delta^{*}$ equal to 0.5 [22]. Different types of synthetic jet actuation have been compared and it was concluded that a purely sinusoidal waveform was more effective up to a deflection angle $\delta^{*}=0.8$ but for higher angles, a pulse-modulated waveform at reduced frequency close to one was more effective while reducing the power by $80 \%$. Like with the studies with sweeping jets, the effect of the actuation location on the model span has been investigated. An actuation on the middle of the span is more effective for $\delta^{*} \leq 0.6$ because of the sweep angle of the model and for $\delta^{*}>0.6$, actuation at the root is more effective. Actuation on the rudder instead of the main body as well as with a blowing angle perpendicular to the rudder hinge line is also more effective. The numerical simulations of Jansen et al. [25] and Shmilovich et al. [26] are in good agreement with the experiment in terms of side force prediction. Simulations allow also to investigate alternative AFC strategies. Shmilovich et al. [26] have shown that putting actuators on the lower half of the model with a blowing velocity doubled is more effective than actuating on the whole model.

Tewes et al. [27] investigated the effect of the sweep angle of the model. They concluded that the actuators act as fluidic boundary layer fences and that a limited number of actuators (two in this case) with a $C_{\mu}$ of $1 \%$ were able to reach the same lift coefficient than twenty nine actuators with a $C_{\mu}$ of 2\%. Like Pack Melton et al. [7]-[11], Kröhnert [31] investigated numerically a simplified two-dimensional configuration. A lift increment of 0.8 was reached with a steady blowing slot with a $C_{\mu}$ of $2.5 \%$. A decrease of the slot width enables a reduction of the mass flow rate to reach the same value of the lift coefficient. In Gebhardt [32], a continuous and a segmented slot were compared and it was observed that a segmented slot enables a reduction of the mass flow rate to reach the same lift increment. Pulsed blowing is also more effective for low values of the lift increment but steady blowing remains more effective for higher values. Löffler et al. [28][30], Staats et al. [29] investigated AFC by pulsed blowing through segmented slot on VTP. A side force increment of 0.2 with a full reattachment of the flow on the rudder deflected at $30^{\circ}$ was obtained for a $C_{\mu}$ of $1.43 \%$. On the same model, Singh \& Scholz [33] studied AFC by passive and fluidic vortex generators (VGs). A side force increment of $10 \%$ was obtained with fluidic VGs for a $C_{\mu}$ of $0.07 \%$.

The present paper is composed of two parts. In the first part, in the same manner as in Pack Melton et al. [7][11], AFC is studied experimentally on a two-dimensional configuration to prepare the wind tunnel tests on the 
VTP. The novelty is that different types of actuation (continuous/pulsed blowing through slots, continuous blowing through segmented slots, sweeping jets) are compared in terms of efficiency on the same model. Then, in a second part, AFC with sweeping jets is tested on a model which is a scale 1:2 vertical tail model of a generic business jet. The effects of the momentum coefficient, actuation location and spanwise spacing are investigated. The Aerodynamic Figure of Merit $n^{\circ} 1$ is also computed for the first time which shows that it is possible to reach values higher than one on this application.

\section{Preliminary test}

\section{A. Experimental set-up and Instrumentation}

Before investigating the effect of sweeping jets on a vertical tail plane, a wind tunnel test has been conducted on a simplified two-dimensional unswept configuration. The model consists of a $0.867-\mathrm{m}$-long flat plate and a nonslotted $0.22 \mathrm{~m}$ chord long flap (20\% of total chord length) with a shape based on a NACA 4412 airfoil. The flap geometry has been chosen in order to have a trailing edge separation. This model has already been used in previous studies of closed-loop control by extremum seeking [1]-[36]. The model is mounted horizontally between two vertical walls distant of $0.8 \mathrm{~m}$ in the ONERA L1 wind tunnel (see Fig. 1).

The flap is equipped with 51 pressure taps chordwise distributed on the flat plate and the flap on both the pressure and suction side. Moreover, 18 pressure taps are distributed in the spanwise direction on two rows to check the flow bidimensionality: one on the flat plate, the other one on the flap.

Carborundum is used at the flat plate leading edge to trigger transition to a fully turbulent boundary layer. The free-stream velocity $U_{\infty}$ is varied between 24.5 and $50 \mathrm{~m} \mathrm{~s}^{-1}$, giving Reynolds numbers between $1.8 \times 10^{6}$ and $3.6 \times 10^{6}$ based on the total length of the model $(1.087 \mathrm{~m})$. The external turbulence level is $0.2 \%$.

Seven actuator segments are integrated into the flap along the span to investigate pulsed blowing actuation. Each of them consists of a fast switching two states solenoid valve (Festo MHE2) which allows compressed air to blow through a 0.25 -mm-wide and 90-mm-long slot covering $80 \%$ of the total flap span. The distance between the slots is $7 \mathrm{~mm}\left(0.9 \%\right.$ of the span). The seven actuators are operated synchronously. The slots are located at $x / c_{f l a p}=8 \%$ and they are downstream inclined at an angle of $30^{\circ}$ with respect to the local flap tangent.

The momentum flux injected in the flow is generally quantified by the so-called momentum coefficient $C_{\mu}$, first introduced by Poisson-Quinton [38][39] for steady blowing. It is similar to a thrust coefficient and is defined as 


$$
C_{\mu}=\frac{\rho_{j e t} U_{j e t}^{2} A_{j e t}}{\frac{1}{2} \rho_{\infty} U_{\infty}^{2} A_{r e f}}=\frac{q_{m} U_{j e t}}{\frac{1}{2} \rho_{\infty} U_{\infty}^{2} A_{r e f}}
$$

where the subscript jet refers to the jet, $\infty$ to the freestream flow, $q_{m}$ is the mass flow rate, $A_{j e t}$ is the total area of all active actuator orifices and $A_{\text {ref }}$ is the wing area. When periodic blowing is considered, the oscillatory momentum coefficient (see Greenblatt and Wygnanski [40]) is defined as

$$
<C_{\mu}>_{t}=\frac{\rho_{j e t}<U_{j e t}^{2}>_{t} A_{j e t}}{\frac{1}{2} \rho_{\infty} U_{\infty}^{2} A_{r e f}}
$$

where $<>_{\mathrm{t}}$ stands for the time averaging operator. In the case of a square excitation of the valve, $U_{j e t}$ is

$$
\left\{\begin{array}{c}
0 \text { if } 0 \leq t / T<D C \\
U_{\text {peak }} \text { if } D C \leq t / T \leq 1
\end{array}\right.
$$

where $D C$ is the duty cycle and $T$ the period. This yields

$$
<U_{j e t}^{2}>_{t}=D C . U_{\text {peak }}^{2} \text { and }<U_{j e t}>_{t}=D C . U_{\text {peak }}
$$

The oscillatory momentum coefficient for a pulsed jet excited with a square signal is finally

$$
<C_{\mu}>_{t}=\frac{1}{D C} \frac{\left.\left.<q_{m}\right\rangle_{t}<U_{j e t}\right\rangle_{t}}{\frac{1}{2} \rho_{\infty} U_{\infty}^{2} S_{\text {ref }}}
$$

where $<q_{m}>_{t}=\rho_{j e t}<U_{j e t}>_{t} A_{j e t}$. Consequently, if the duty cycle is $50 \%$, the oscillatory momentum coefficient $\left\langle C_{\mu}>\right.$ is twice the 'steady' ( $\left.D C=1\right)$ momentum coefficient $C_{\mu}$ for the same mass flow rate. Said otherwise, it means that pulsed blowing requires a time-averaged mass flow rate $1-\sqrt{D C}=1-\sqrt{0.5}=-29 \%$ smaller to have the same momentum coefficient $C_{\mu}$. Unfortunately, the power coefficient $C_{\pi}=\frac{q_{v}\left(P_{j e t}-P_{\infty}\right)}{\frac{1}{2} \rho_{\infty} U_{\infty}^{3} A_{r e f}}$ increases when $D C$ decreases for a given time-averaged mass flow rate since the jet stagnation pressure $P_{\text {jet }}$ has to be increased to keep the time-averaged mass flow rate constant. So, it is possible to decrease the required timeaveraged mass flow rate to reach a given $C_{\mu}$ value by decreasing $D C$ but the power consumption will increase. It is the same issue with reducing the actuator orifice areas. Since the velocity is squared in the numerator of the $C_{\mu}$ coefficient, decreasing the exit orifice area for a given mass flow rate increases the momentum coefficient but also the power coefficient. 


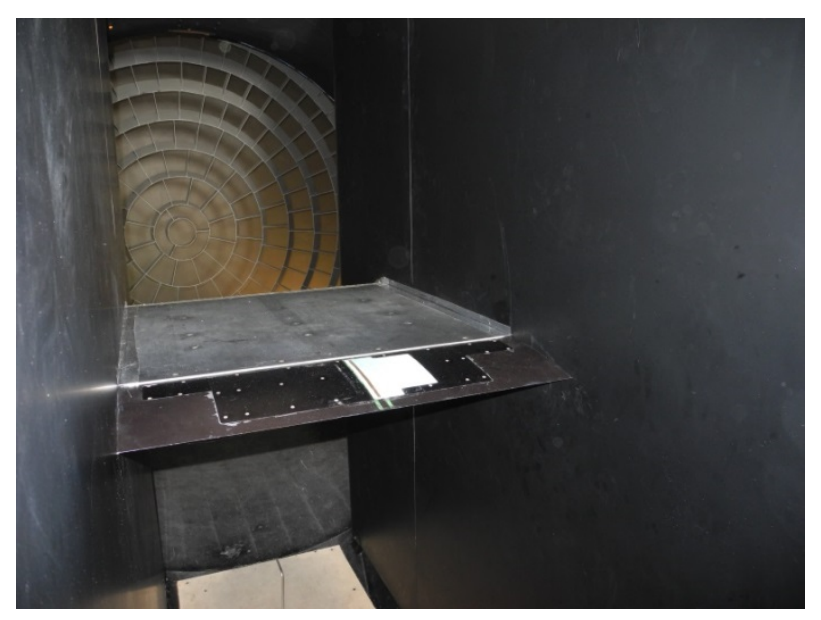

Fig. 1 Flat plate model with hinged slotless flap in the L1 wind tunnel.

\section{B. Results}

\section{Baseline}

First, the effect of the Reynolds number on the lift curve has been investigated. Fig. 2 shows the lift evolution with the flap deflection angle for three freestream velocities. The lift coefficient is obtained by pressure integration. For small flap angle, lift increases linearly. Then, for $\delta \geq 10^{\circ}$, the lift slope decreases with the growing separation on the flap. A lift plateau is visible between $\delta=20^{\circ}$ and $24^{\circ}$. This figure also shows that the effect of the Reynolds number is very limited since all the curves are nearly collapsed. Fig. 3 shows the wall pressure distribution for several flap deflection angles. A separation appears at the flap trailing edge for $\delta=10^{\circ}$ and then it grows with the deflection angle up to $\delta=30^{\circ}$ where the flow on the flap is fully separated. The $C_{p}$ peak at $x / c=7 \%$ corresponds to the transition trip.

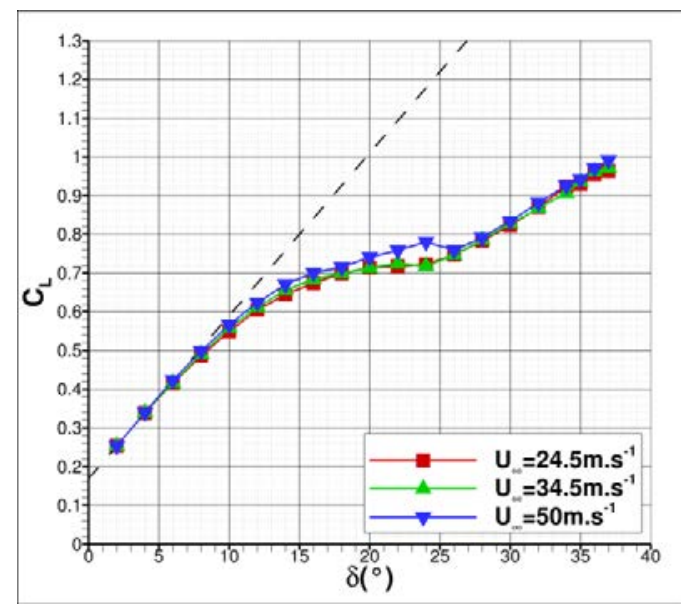


Fig. 2 Lift coefficient as function of flap deflection angle.

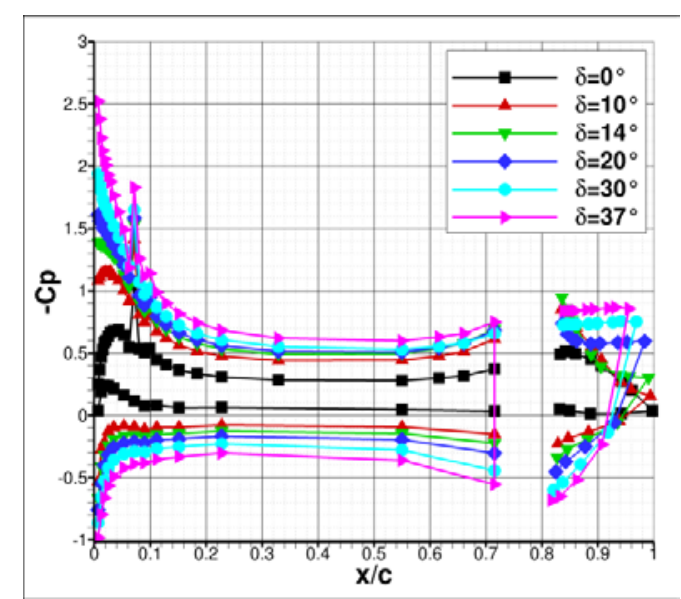

Fig. 3 Wall pressure coefficient for different flap deflection angles $\left(U_{\infty}=34.5 \mathrm{~m} . \mathrm{s}^{-1}\right)$.

\section{Steady blowing}

First, the effect of steady blowing through the slots located at the flap leading edge is investigated. The effect of the momentum coefficient $C_{\mu}$ is shown in Fig. 4. The effect of the steady control is to delay the flow separation on the flap since the linear portion of the lift curve grows as $C_{\mu}$ increases. One can also observe that for $C_{\mu}$ values higher than $0.146 \%$ lift is increased even for low flap angles which means that actuation is in a circulation control mode. For the lowest $C_{\mu}$ value of $0.029 \%$ which corresponds to a velocity ratio lower than one (0.9), lift is lower than the baseline case for $\delta \leq 16^{\circ}$. Despite this, there is a small lift increment for $20^{\circ} \leq \delta \leq 30^{\circ}$.

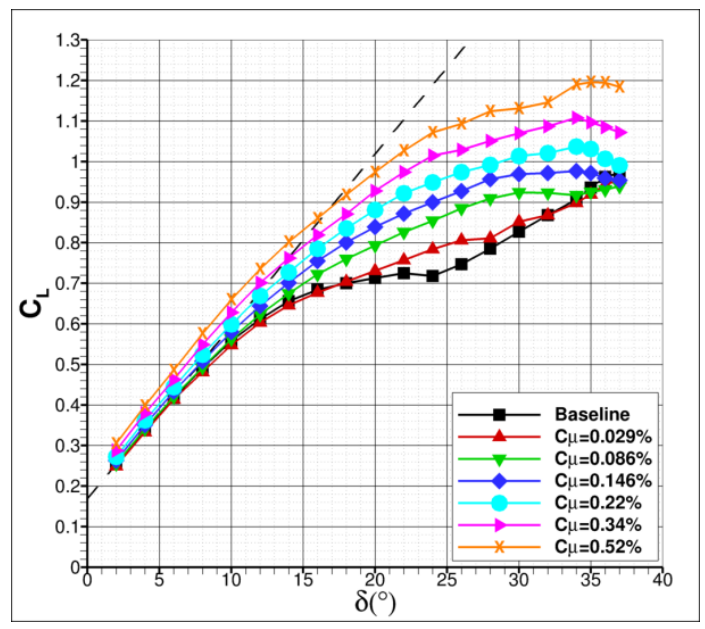

Fig. 4 Lift polars with steady blowing $\left(U_{\infty}=34.5 \mathrm{~m} . \mathrm{s}^{-1}\right)$. 


\section{Pulsed blowing}

The effect of pulsed blowing actuation has then been investigated with the objective of decreasing the mass flow rate required to reattach the flow thanks to the excitation of the natural flow instabilities like the vortex shedding phenomenon due to the separation on the flap. In this section, the duty cycle $(D C)$ value is fixed equal to $50 \%$. First, the effect of the pulsed blowing frequency on lift has been studied for a deflection angle where the flow on the flap is fully separated (see Fig. 5). The reference length scale used to non-dimensionalize the frequency corresponds to the flap wake height $c_{f l a p} \cdot \sin (\delta)$. An optimal Strouhal number around 0.2 is found which corresponds to the frequency of vortex shedding phenomenon as observed by the analysis of the uncontrolled flow (see [36] for more details). Fig. 6 shows the effect of momentum coefficient on the lift curve for a constant forcing frequency corresponding to the optimal one at $\delta=35^{\circ}$. As for the steady blowing cases, pulsed blowing allows to delay the flow separation appearance to higher deflection angles which is marked by an extended linear zone. The comparison with steady blowing will be performed in a following section.

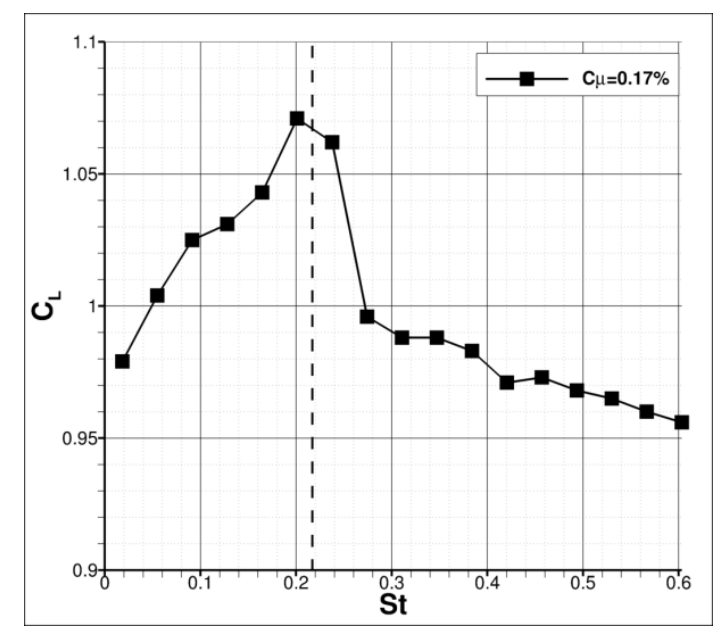

Fig. 5 Effect of pulsed blowing Strouhal number on lift for $\delta=35^{\circ}\left(U_{\infty}=34.5 \mathrm{~m} . \mathrm{s}^{-1}\right)$. 


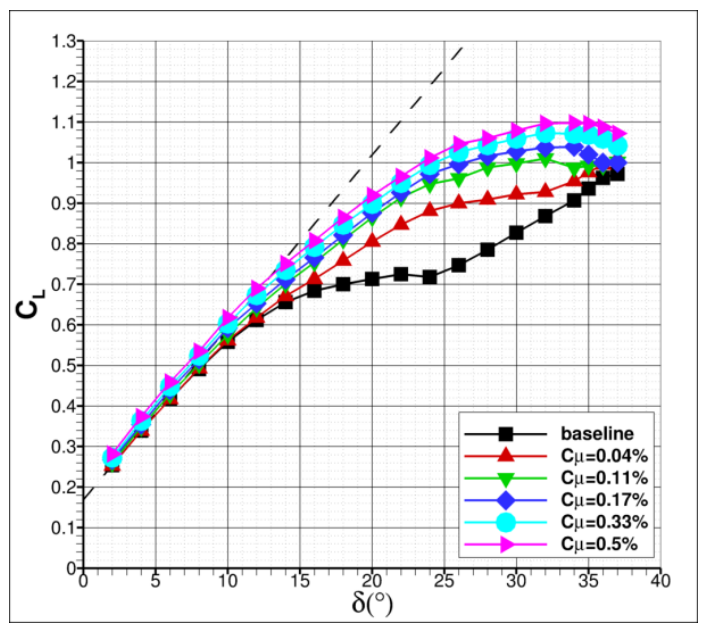

Fig. 6 Lift polars with pulsed blowing at $S t=0.2\left(U_{\infty}=34.5 \mathrm{~m} . \mathrm{s}^{-1}\right)$.

\section{Segmented slot}

Before testing the sweeping jets in the next section, the effect of a segmented slot which will create 3D effects on the flow (contrary to the two previous sections where the effect of the control was mostly 2D) has been investigated like in Gebhart [32]. Since the sweeping jets will blow through isolated slots with a spanwise spacing of several percent of the span, the idea was to investigate the effect of this segmentation of the blowing alone without the additional sweeping effect. In addition to this 3D effects, as already explained in section A, by looking at the definition of the momentum coefficient $C_{\mu}$, one can expect that since the slot area has been decreased, for the same mass flow rate value, the blowing velocity $U_{\text {jet }}$ will be higher and consequently $C_{\mu}$ will also be higher. So, if the $C_{\mu}$ coefficient is the right non-dimensionalized parameter, the lift increment should be larger. Two different spanwise spacings have been investigated: $5.6 \%$ and $10 \%$ of the span (see Fig. 7). The blowing is steady and no pulsing has been investigated. In both cases, the blowing slot has a length of $1.25 \%$ of the span and the same width than the continuous and pulsed blowing slots previously tested.

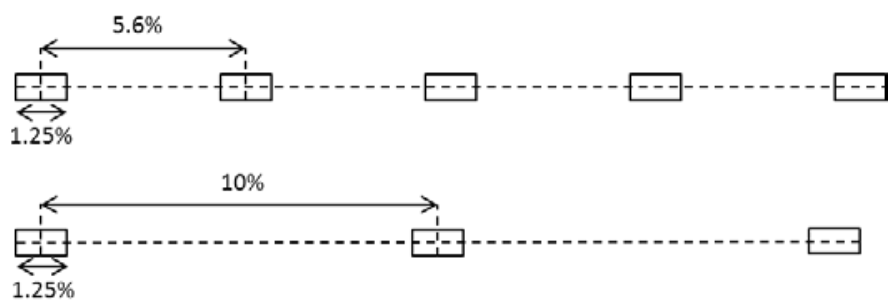

Fig. 7 Sketch of the two segmented slots. 
Fig. 8 shows the effect of these segmented slots on the lift curve compared with the previously tested steady blowing slot. For moderate flap deflection angles $\left(0 \leq \delta \leq 22^{\circ}\right)$, the lift curves of the segmented slot cases at $C_{\mu}=$ $0.23 \%$ and $0.27 \%$ is close to the steady blowing one at $C_{\mu}=0.22 \%$ which means that the $C_{\mu}$ coefficient is the good non-dimensionalized parameter. For higher deflection angles $\left(\delta \geq 28^{\circ}\right)$, the segmented slot is less effective to delay flow separation and the lift coefficient is closer the steady blowing case at $C_{\mu}=0.086 \%$. This means that steady blowing through a 2D slot is more effective than blowing through a segmented slot for large deflection angle. The lift coefficient for the case with a small spacing of $5.6 \%\left(C_{\mu}=0.27 \%\right)$ is higher than for the large spacing case with $s=10 \%$ for $\delta \leq 20^{\circ}$ and it is the opposite for $\delta \geq 22^{\circ}$. A larger spacing is more effective for large deflection angle.

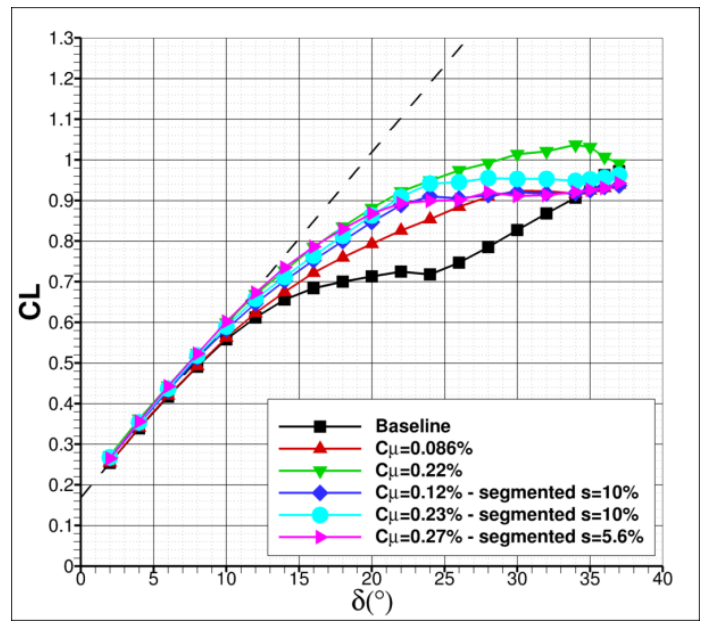

Fig. 8 Comparison of lift polars between continuous and segmented blowing slots $\left(U_{\infty}=34.5 \mathrm{~m} . \mathrm{s}^{-1}\right)$.

\section{Sweeping jets}

Sweeping jets have also been investigated. They have a curved geometry like in Raman \& Raghu [4]. The orifice dimensions are a width of $1 \mathrm{~mm}$ and a length of $2 \mathrm{~mm}$. The orifice spacing is equal to $27 \mathrm{~mm}(\mathrm{~s}=3.3 \%$ of model span or 13.5 orifice length). Fig. 9 shows a picture of one of the four inserts manufactured using rapid prototyping. There are six sweeping jets for each insert.

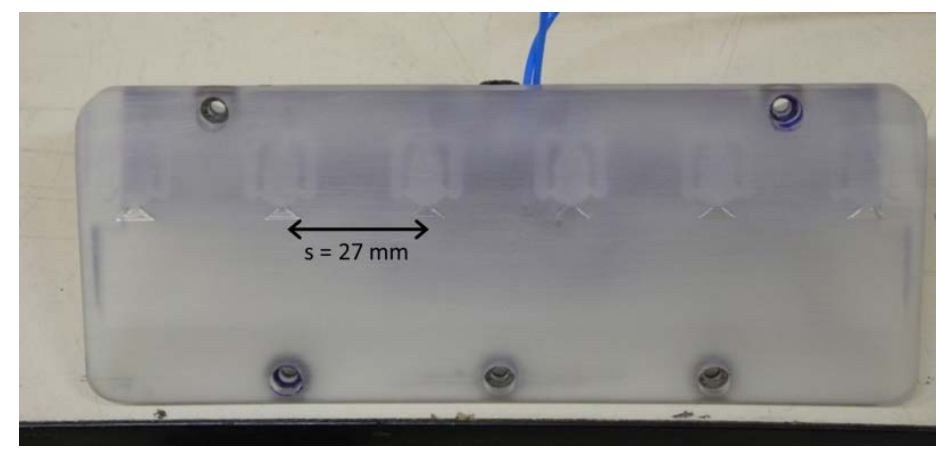


Fig. 9 Sweeping jets.

Fig. 10 shows the effect of the momentum coefficient on the lift curve with sweeping jets. Like with steady blowing slots, there is a lift increment even for attached flows at low deflection angle values. Non-sweeping jets have also been investigated by manufacturing the same sweeping jets as in Fig. 9 but without the two feedback channels. Fig. 11 shows the comparison of the lift curves between sweeping and non-sweeping jets. The sweeping provides an additional lift increment of the order of $25 \%$ around $20^{\circ}$. For $\delta \leq 15^{\circ}$ or $\delta \geq 25^{\circ}$, the lift gain is much more limited.

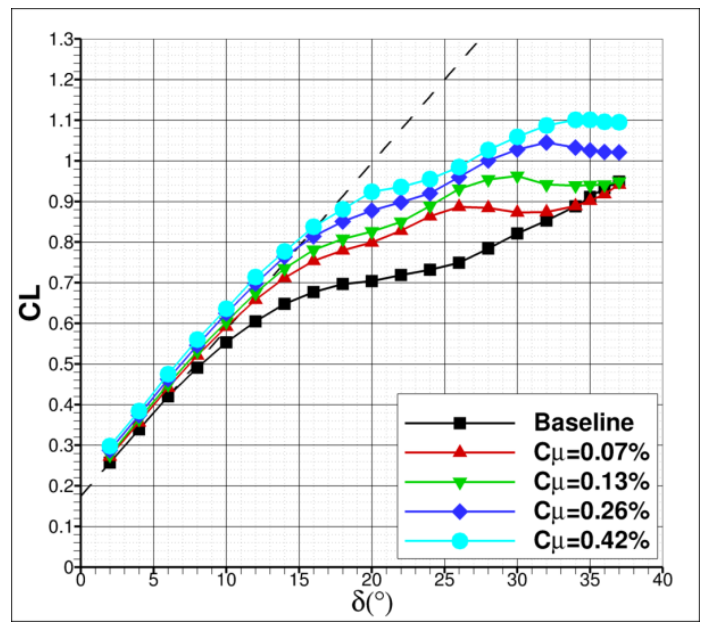

Fig. 10 Lift polars with sweeping jets $\left(U_{\infty}=34.5 \mathrm{~m} . \mathrm{s}^{-1}\right)$.

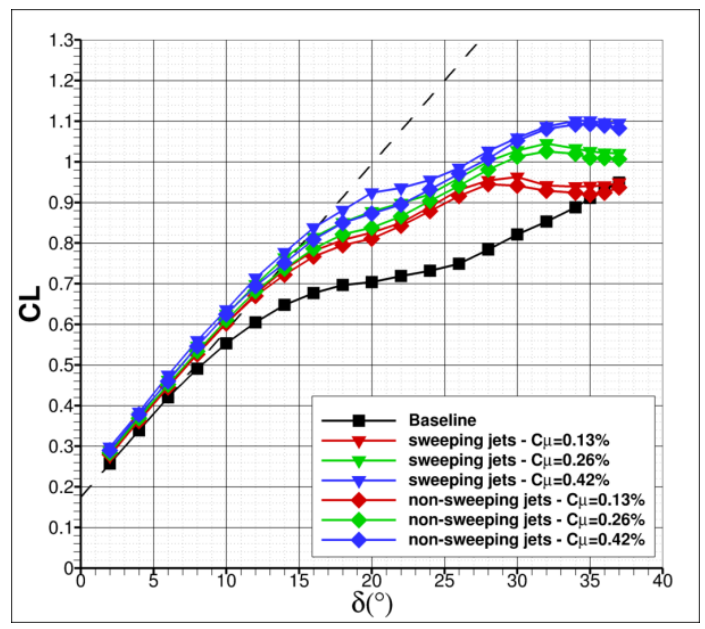

Fig. 11 Comparison of lift polars between sweeping and non-sweeping jets $\left(U_{\infty}=34.5 \mathrm{~m} . \mathrm{s}^{-1}\right)$. 


\section{Comparison between continuous/pulsed blowing, segmented slot and sweeping jets}

To summarize all the results, the lift increment at $\delta=20^{\circ}$ has been plotted as function of the momentum coefficient $C_{\mu}$ for the three freestream velocities (Fig. 12). One can observe that there is a good collapse of all the results despite the different types of actuation: steady blowing through 2D or segmented slots, pulsed blowing and sweeping jets. The lift increment follows a law proportional to the square root of $C_{\mu}$ (dashed line). The results with pulsed blowing depart slightly from this trend with a higher lift gain for low $C_{\mu}$ values and a lower one for high $C_{\mu}$ values. This is something which has already been observed by Gebhardt [32] who concluded that pulsed blowing is more effective than steady blowing for low $C_{\mu}$ values and the opposite conclusion for high $C_{\mu}$ values. One can also observe that the higher the freestream velocity, the (slightly) higher the lift increment with sweeping jets. This is something which will be retrieved in the next part of the paper on a different model.

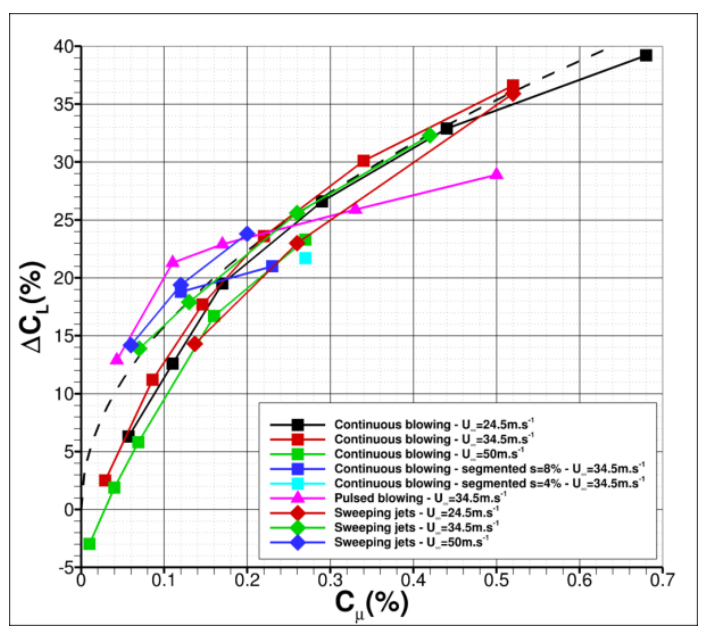

Fig. 12 Lift increment at $\delta=20^{\circ}$ as function of momentum coefficient $C_{\mu}$.

To emphasize the potential mass flow rate reduction, the lift increment has been plotted as function of the timeaveraged mass flow rate in Fig. 13 (left). For example for a lift gain of 20\%, pulsed blowing, segmented slots and sweeping jets allow a reduction of the mass flow rate by a factor $2\left(7 \mathrm{~g} . \mathrm{s}^{-1}\right.$ instead of $\left.14 \mathrm{~g} . \mathrm{s}^{-1}\right)$ compared to steady blowing slots. This is partly due to higher peak velocities (for a given $C_{\mu}$ value) due to the pulsation or the reduced orifice area (segmented slot, sweeping jets) but also to 3D effects (segmented slots and sweeping jets create counterrotating streamwise vortices as shown by Woszidlo \& Wygnanski [6]) or flow instability excitation (pulsed blowing slot) without the possibility to separate these different effects. Nevertheless, Fig. 13 (right) shows that these mass flow rate reductions come with the expense of higher power coefficients $C_{\pi}$ in the case of segmented slots and 
sweeping jets. This is in agreement with what has already been observed in the literature [8]. There is just the pulsed blowing slot which provides both a reduction of the mass flow rate and the power coefficient but only for $C_{\mu}$ values lower than $0.17 \%$. The effect of the duty cycle of the pulsed blowing excitation has also been investigated by varying DC between $20 \%$ and $100 \%$. The time-averaged mass flow rate has been kept constant while varying the $D C$ value which explains why this curve in Fig. 13 (left) is vertical. For $D C=100 \%$, it corresponds to the steady blowing case and for $D C=50 \%$, it corresponds to the pulsed blowing case previously tested. This curve shows that it is possible to improve slightly the lift gain by decreasing the duty cycle value below $50 \%$. But, like the other pulsed blowing cases or the segmented slot and the sweeping jets, this mass flow rate reduction comes with the expense of a higher power coefficient $C_{\pi}$ since to keep the time-averaged mass flow rate constant when the duty cycle decreases, the jet velocity has to be increased.

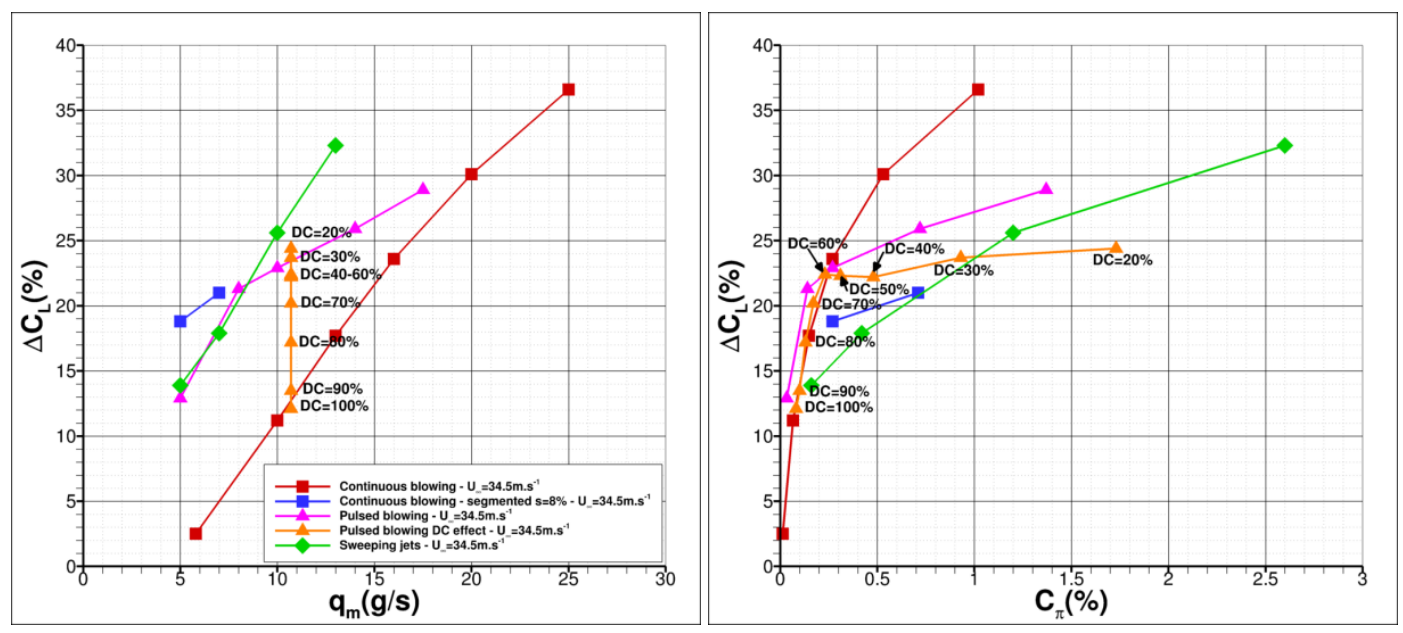

Fig. 13 Lift increment at $\delta=20^{\circ}$ as function of time-averaged mass flow rate (left) and power coefficient (right) for $U_{\infty}=34.5 \mathrm{~m} . \mathrm{s}^{-1}$.

To summarize the results, it has been observed that the $C_{\mu}$ coefficient is a good non-dimensionalized parameter which allows to collapse the lift increments from different types of actuation (continuous/pulsed blowing, segmented slot, sweeping jets) on a single curve which follows a law proportional to the square root of $C_{\mu}$. The use of pulsed blowing, segmented slots or sweeping jets allow a reduction of a factor two of the mass flow required to reach a $20 \%$ lift increment but the drawback is a higher power coefficient. Since the sweeping jets have exhibited a good compromise between simplicity (no actuator contrary to pulsed blowing) and mass flow rate reduction for a given 
lift increment, they have been selected to be tested on a vertical tail plane to delay the separation which appears on the flap for high deflection angles.

\section{Vertical tail plane}

\section{A. Experimental set-up and Instrumentation}

Fig. 14 shows a picture of the vertical tail plane model installed in the ONERA L1 wind tunnel. The model corresponds to a scale 1:2 vertical tail plane of a generic business jet. The wing is tapered and swept back with an angle $\Lambda=43.6^{\circ}$ at the leading edge. The chord length is equal to $1.677 \mathrm{~m}$ at the root and $0.717 \mathrm{~m}$ at the tip which gives a mean aerodynamic chord equal to $1.263 \mathrm{~m}$. The flap chord length evolves from $23.7 \%$ of the total chord length at the root to $40 \%$ at the tip. The model height is $1.5 \mathrm{~m}$. The closed loop wind tunnel's test section has a diameter of $2.4 \mathrm{~m}$ and is operated at speeds ranging between 34 and $68 \mathrm{~m} \cdot \mathrm{s}^{-1}(M=0.1$ and 0.2$)$ for this experiment. A transition trip (zig-zag tape) has been applied at $x / c=1 \%$ on both sides of the model.

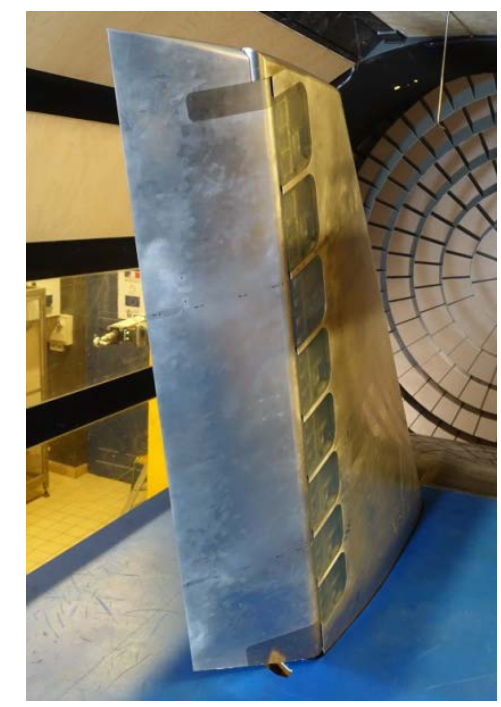

Fig. 14 Vertical tail plane model in the L1 wind tunnel.

Fig. 15 shows the six-component balance below the wind tunnel. The balance has an axial force range of $4500 \mathrm{~N}$, side force range of $30.000 \mathrm{~N}$ and vertical force range of $132.000 \mathrm{~N}$, all within an accuracy of $0.1 \%$ of their respective full scale. In addition, the model is equipped with two rows of 44 and 56 pressure taps, respectively (see Fig. 16). 


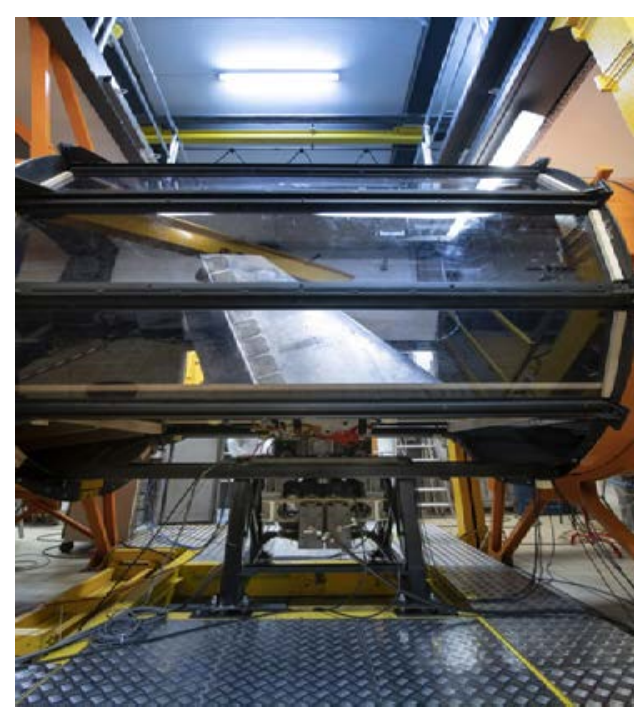

Fig. 15 Model set-up with balance.

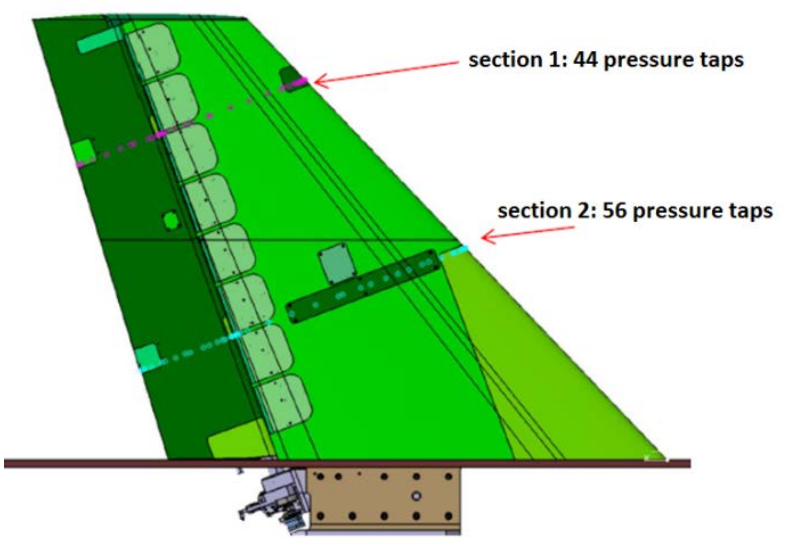

Fig. 16 Position of chordwise pressure taps rows.

Fig. 17 shows the sweeping jets installed on the model. It consists in eight 3D printed blocks of four sweeping jets. They were supplied with compressed air through the root of the model. Hose forces due to the air supply pipes passing through the balance are mitigated by use of internal decoupling devices. The blowing mass flow was recorded by a flow meter. All 32 actuators are located at the trailing edge of the main element. The sweeping jet geometry is the same as in the preliminary test but with a scale 1.5:1 corresponding to ratio of the flap chord lengths. The exit orifice dimensions are a width of $1.5 \mathrm{~mm}$ and a length of $2.63 \mathrm{~mm}$. The ejection angle relative to the surface is equal to $10^{\circ}$ and the narrowest achievable spacing is $44 \mathrm{~mm}$ ( $s=2.9 \%$ of model span or 17 orifice length). The narrowest spacing is close to the one in the preliminary test. 

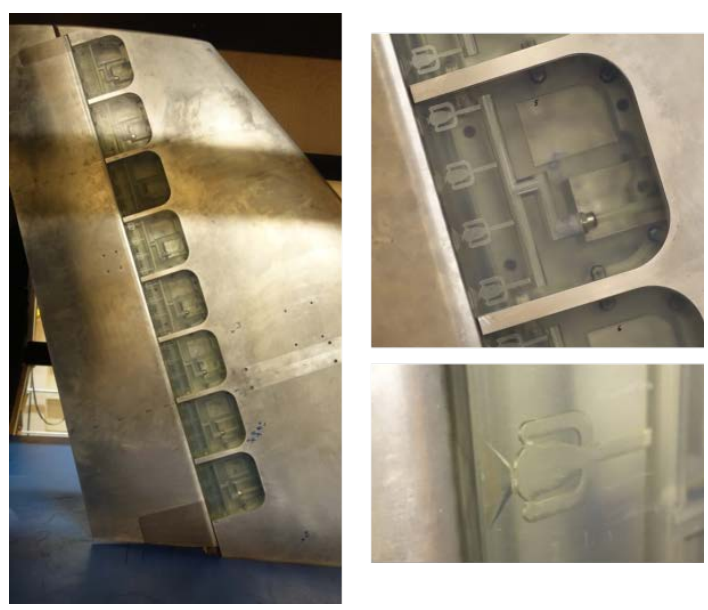

Fig. 17 Sweeping jets (left: the eight modules installed in the model, right: zoom on one module (top) and one sweeping jet (bottom)).

\section{B. Results}

\section{Baseline}

First, the effect of the Reynolds number on the baseline configuration without control has been investigated. Fig. 18 shows the lift curve for three freestream velocities: $U_{\infty}=34 \mathrm{~m} . \mathrm{s}^{-1}\left(R e_{c}=2.87 \times 10^{6}\right), 50 \mathrm{~m} . \mathrm{s}^{-1}\left(R e_{c}=4.19 \times 10^{6}\right)$ and $68 \mathrm{~m} . \mathrm{s}^{-1}\left(R e_{c}=5.66 \times 10^{6}\right)$. The three curves are very similar with a slightly higher lift for the lowest freestream velocity. The lift curves start to deviate from the linear zone for $\delta \geq 16^{\circ}$.

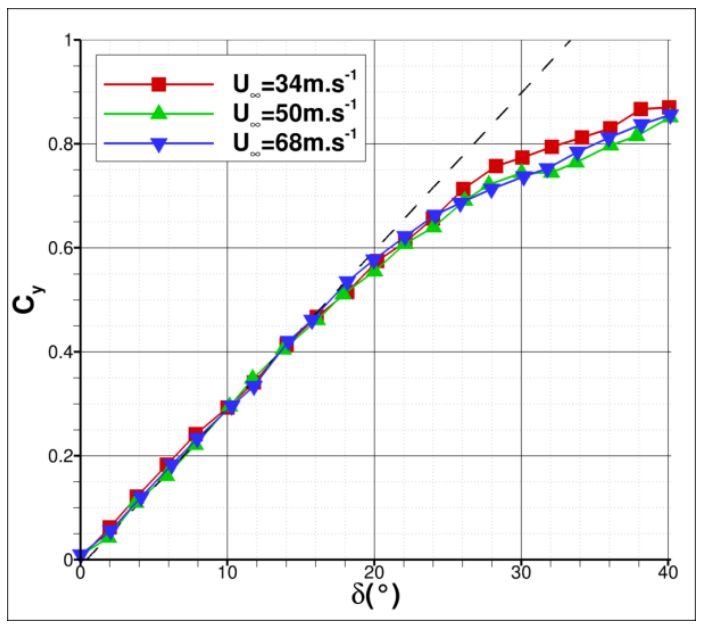

Fig. 18 Side force polars without control. 


\section{Momentum coefficient effect}

Fig. 19 shows the effect of the momentum coefficient on the side force coefficient for a freestream velocity $U_{\infty}=68 \mathrm{~m} \cdot \mathrm{s}^{-1}$ which corresponds to a realistic take-off or landing speed. The higher the $C_{\mu}$ coefficient, the higher the rudder deflection angle from which the curve deviate from the linear trend and consequently the higher the maximum $C_{y}$ coefficient. For $C_{\mu}=0.86 \%$, the side force evolution remains close to the linear slope up to very high values of the deflection angle. The effect of $C_{\mu}$ on the wall pressure distribution is shown in Fig. 20. For section 1 , which is the upper one (see Fig. 16), the flow remains attached up to $\delta=40^{\circ}$ for $C_{\mu}=0.86 \%$ which explains why the lift curve remains linear up to large deflection angles. For section 2, which is the lower one with also the larger chord length for both the main body and the rudder, the flow remains attached up to $\delta=30^{\circ}$ for $C_{\mu}=0.86 \%$. A higher $C_{\mu}$ value would be required to reattach the flow at the wing root.

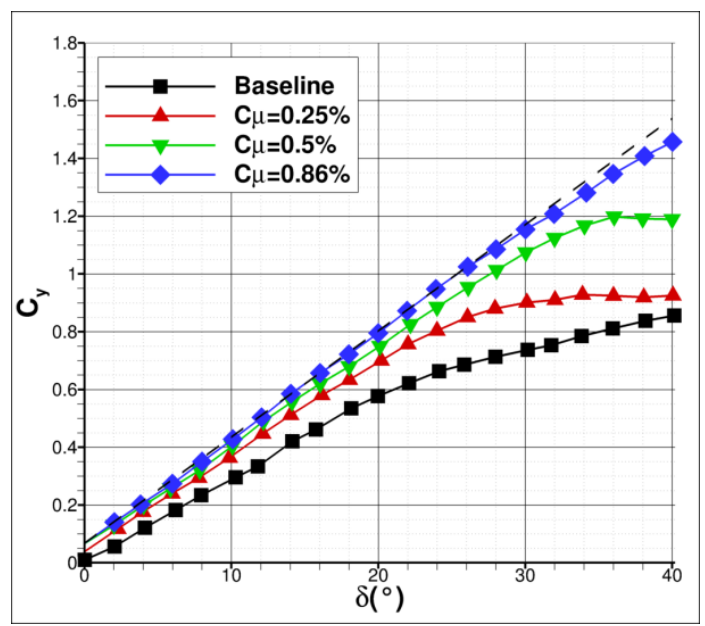

Fig. 19 Side force polars with control $\left(U_{\infty}=68 \mathrm{~m} \cdot \mathrm{s}^{-1}\right)$.

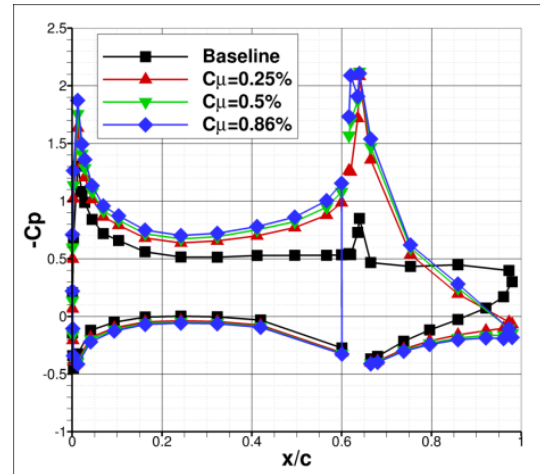

(a) $\delta=20^{\circ}$ - section 1

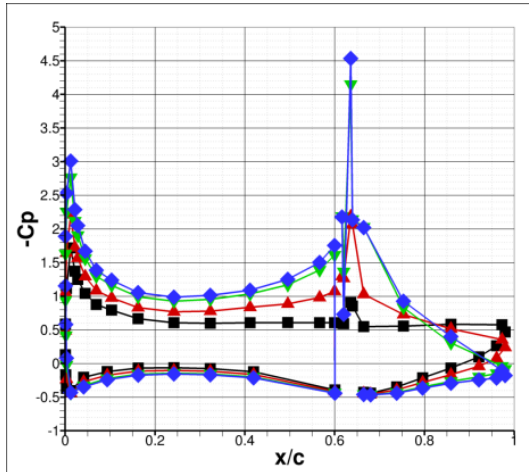

(b) $\delta=30^{\circ}$ - section 1

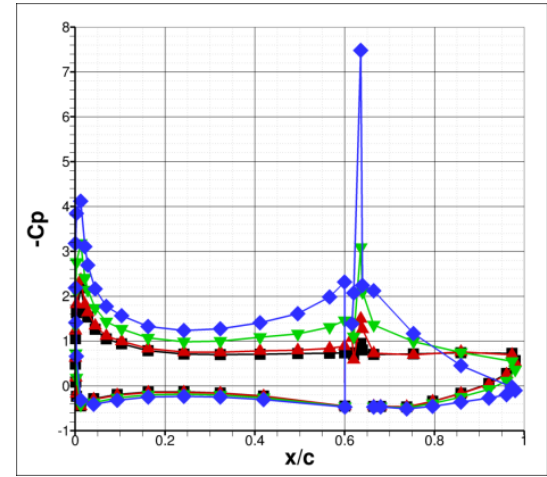

(c) $\delta=40^{\circ}$ - section 1 


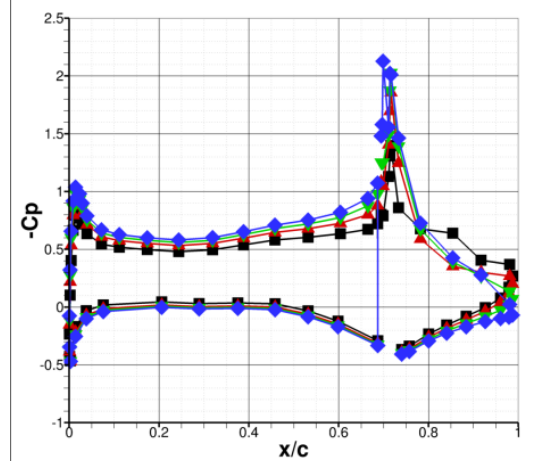

(d) $\delta=20^{\circ}$ - section 2

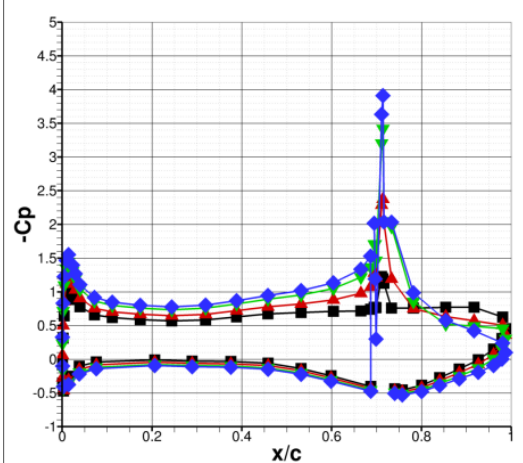

(e) $\delta=30^{\circ}$ - section 2

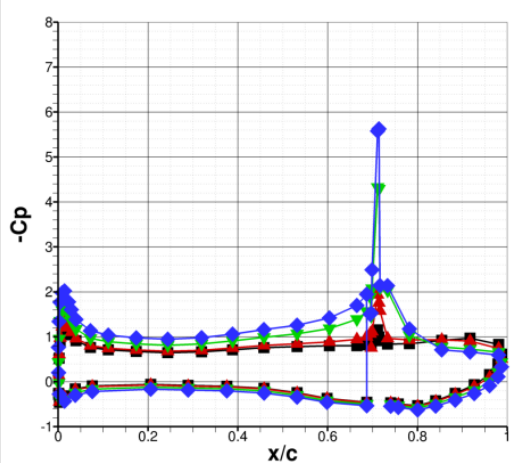

(f) $\delta=40^{\circ}$ - section 2

Fig. 20 Wall pressure distributions for two sections and three rudder deflection angles $\left(U_{\infty}=68 \mathrm{~m} \cdot \mathrm{s}^{-1}\right)$.

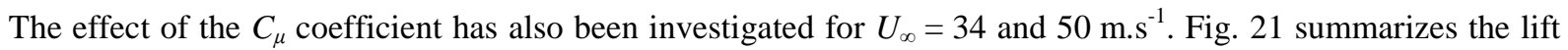
increment obtained for the three freestream velocities and for three rudder deflection angles: $\delta=20^{\circ}, 30^{\circ}$ and $40^{\circ}$. An arrow mark the conditions for which the flow at the sweeping jet exit is sonic. As expected, the larger the rudder deflection angle, the larger the momentum coefficient required to reattach the flow. For $\delta=20^{\circ}$, it is remarkable that for the three freestream velocities the lift increment curves are collapsed to a single law which is proportional to the square root of $C_{\mu}$. The side force increment does not evolve linearly or with $\tan \left(C_{\mu}\right)$ like in Poisson-Quinton \& Lepage [39] but the shape of these curves is in agreement with the other studies which used sweeping jets as presented in the introduction. For $\delta=30^{\circ}$ and $40^{\circ}$, the lift increment still follows a square root law but the curves are not collapsed and the higher the freestream velocity, the larger the lift increment. This is something which had already been observed in the first part of the paper with a completely different model (see Fig. 12). To try to improve the collapse between all results, the side force increment has been plotted as function of the mass flow coefficient $C_{Q}$ (Fig. 22). The collapse between all curves is greatly improved.

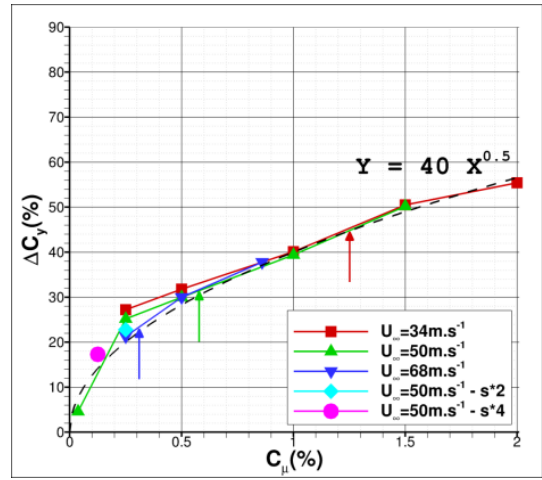

(a) $\delta=20^{\circ}$

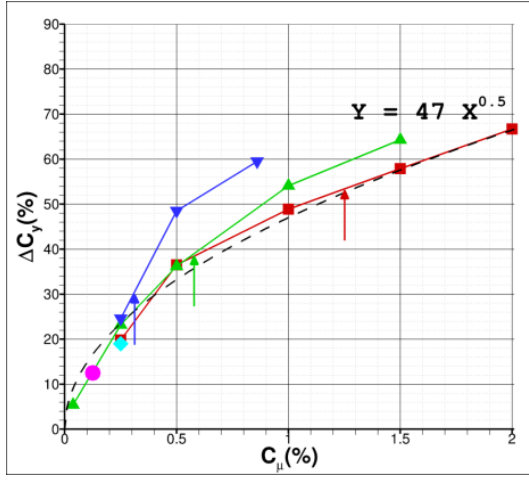

(b) $\delta=30^{\circ}$

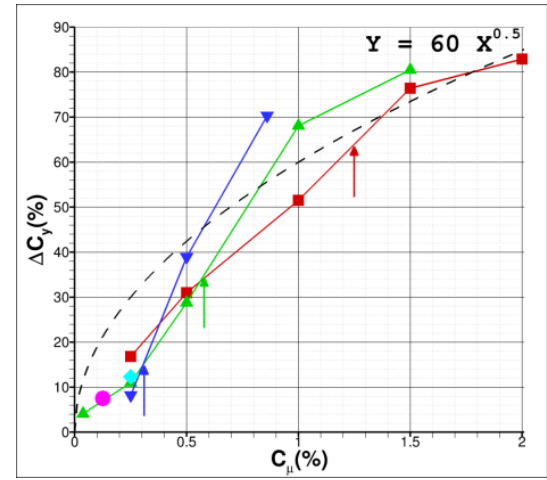

(c) $\delta=40^{\circ}$

Fig. 21 Side force increment as function of momentum coefficient $C_{\mu}$ for three rudder deflection angles. 


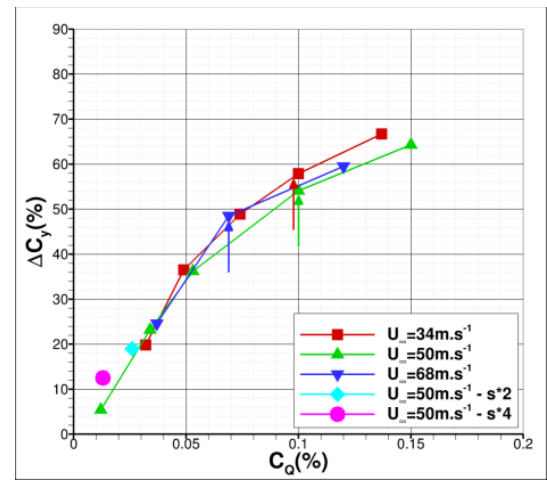

(a) $\delta=30^{\circ}$

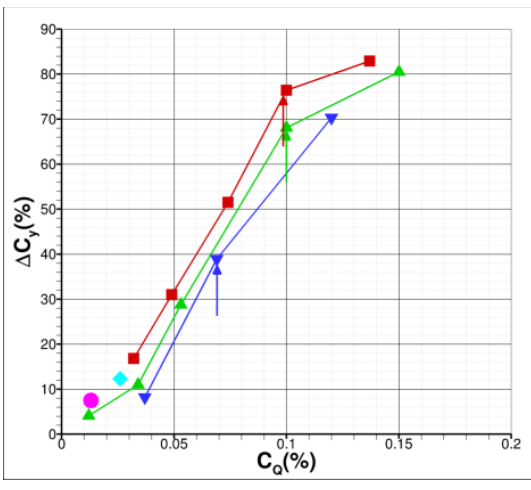

(b) $\delta=40^{\circ}$

Fig. 22 Side force increment as function of mass flow coefficient $C_{Q}$ for two rudder deflection angles.

In Fig. 23, the side force increment has been plotted as function of the power coefficient $C_{\pi}$. Like for the $C_{\mu}$ coefficient, the collapse between all results at different freestream velocities is quite good for $\delta=20^{\circ}$ but the curves deviate from each other for $\delta=30^{\circ}$ and $40^{\circ}$. The curves seem to follow a law proportional to the cubic root of $C_{\pi}$.

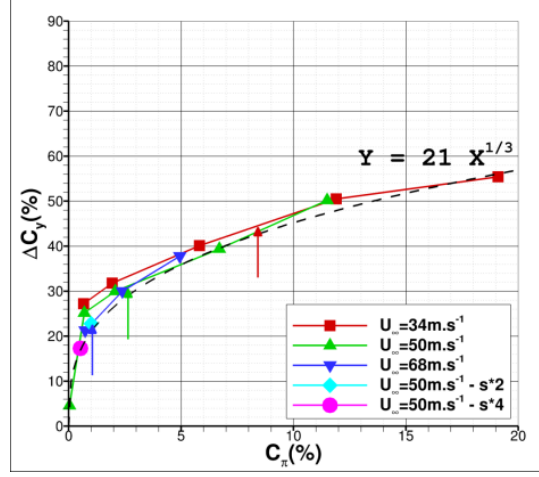

(a) $\delta=20^{\circ}$

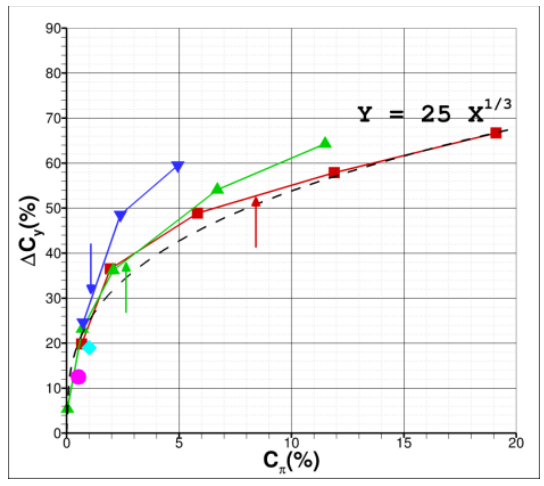

(b) $\delta=30^{\circ}$

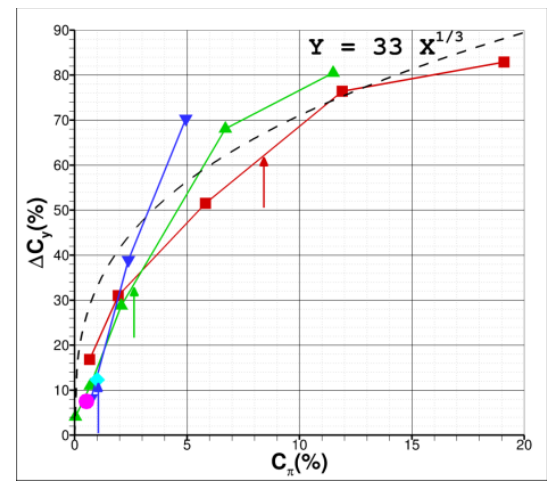

(c) $\delta=40^{\circ}$

Fig. 23 Side force increment as function of power coefficient $C_{\pi^{*}}$

Fig. 24 shows the drag polars for $U_{\infty}=50 \mathrm{~m} \cdot \mathrm{s}^{-1}$. The $C_{\mu}$ coefficient has been added to the drag coefficient $C_{x}$ to take into account the thrust generated by the control. This ensures a good collapse of all the curves for low rudder deflection angle. The effect of the control is not only to increase the side force coefficient but also to reduce drag and in particular the pressure drag by delaying the separation appearance on the rudder. For example, for $C_{\mu}=0.5 \%$, the drag is decreased by $26 \%$ at $C_{y}=0.5$ and by $44 \%$ at $C_{y}=0.8$. 


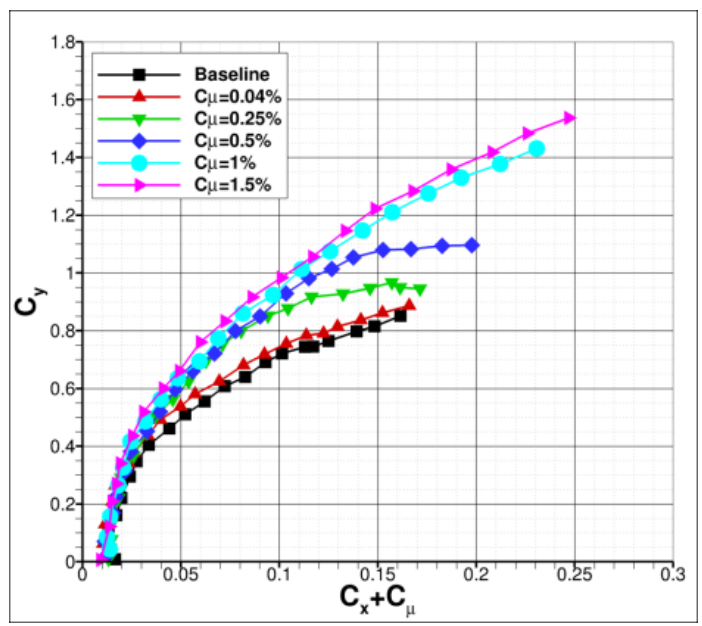

Fig. 24 Side force vs drag $\left(U_{\infty}=50 \mathrm{~m} \cdot \mathrm{s}^{-1}\right)$.

It is also interesting to evaluate the energy efficiency of the control by computing the first "Aerodynamic Figure of Merit” AFM1 as defined by Seifert [41] which is the ratio of the lift-to-drag ratio with control (taking into account the power coefficient $C_{\pi}$ ) to the lift-to-drag ratio without control. Fig. 25 shows $A F M 1$ as function of the side force coefficient. To reach AFM1 higher than 1, there are two possibilities: a normally loaded wing $\left(C_{y}<1\right)$ with a low $C_{\mu}$ value $\left(C_{\mu} \leq 0.25 \%\right)$ or a reduced wing area, highly loaded $\left(C_{y}>1.5\right)$, with a high $C_{\mu}$ value $\left(C_{\mu}=1 \%\right)$.

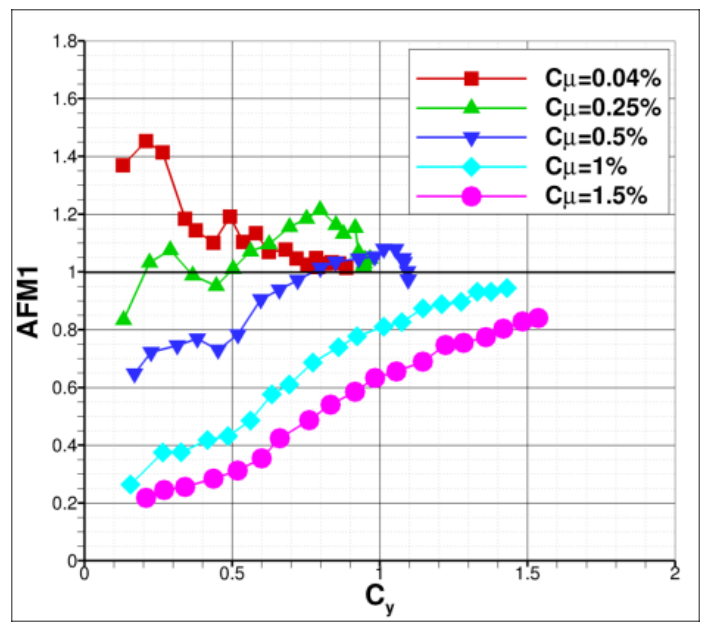

Fig. 25 Aerodynamic Figure of Merit as function of the side force coefficient $\left(U_{\infty}=50 \mathrm{~m} \cdot \mathrm{s}^{-1}\right)$.

\section{Actuation location and spanwise spacing effects}

The effect of the actuation location has also been investigated. Two locations have been tested: lower side of the model (lower four modules in Fig. 17) or upper side (upper four modules). Fig. 20 has shown that it was easier to 
suppress the flow separation in section 1 than in section 2 because the latter has a larger chord length [6]. Fig. 26 (left) shows the effect of the actuation location on the side force curve. The actuation on the lower side of the model leads to slightly higher lift increment than on the upper side probably because the chord length is larger on the lower side. In both cases, the side force coefficients with a $C_{\mu}$ of $0.5 \%$ are close to the one with a $C_{\mu}$ of $0.25 \%$ on the whole wing which corresponds to a mass flow rate $28 \%$ lower. So, the actuation on one side of model is not effective.

Concerning the effect of the spacing between sweeping jets, in addition to the initial spacing $s$ of $2.9 \%$ of the model span, two other spacings have been tested: the initial one multiplied by two ("s*2" curve) or by four ( $\mathrm{s}^{*} 4$ curve). For the doubled spacing case, the side force curve is close to the original spacing one with the same $C_{\mu}$ coefficient which means that this coefficient is the good non-dimensionalized parameter. The effect on the side force increment is shown in Fig. 21. The results with a larger spacing follow the same trend as the baseline spacing one. Fig. 22 (a) shows that these larger actuator spacing allow a reduction of the mass flow rate to reach the same side force increment especially for the spacing multiplied by four case (-38\%). But the drawback is that the power coefficient $C_{\pi}$ is higher for these increased spacing cases because the stagnation pressure has to be increased to reach the same value of the $C_{\mu}$ coefficient since the number of actuator has been decreased.
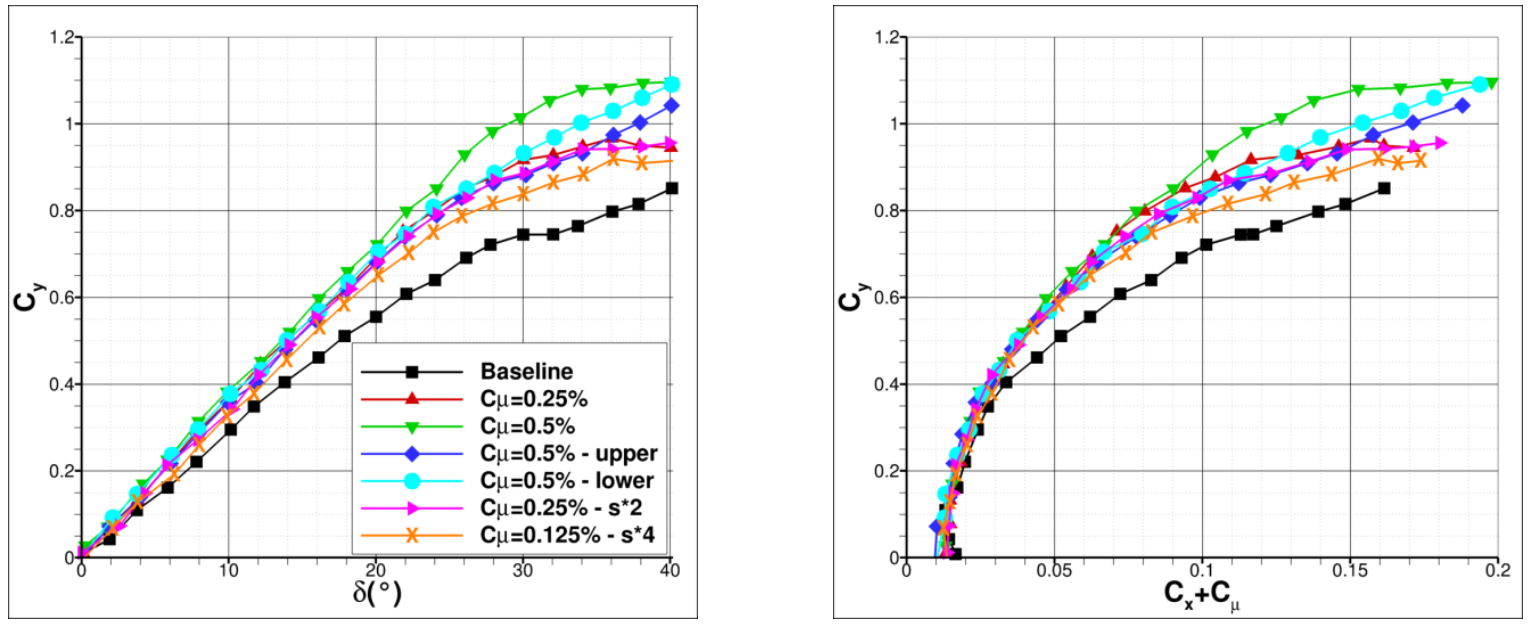

Fig. 26 Side force and drag polars $\left(U_{\infty}=50 \mathrm{~m} \cdot \mathrm{s}^{-1}\right)$.

\section{Conclusions}

In the first wind tunnel test, different types of actuation (continuous/pulsed blowing, segmented slots, sweeping jets) have been compared on a simple flat model with a hinged slotless flap. First, it has been observed that the $C_{\mu}$ coefficient is a good non-dimensionalized parameter which allows to gather the lift increments from these different 
types of actuation on a single curve which follow a law proportional to the square root of $C_{\mu}$. The use of pulsed blowing, segmented slots or sweeping jets allow a reduction of a factor two of the mass flow rate required to reach a $20 \%$ lift increment but the drawback is a higher power coefficient. This is partly due to higher peak velocities (for a given $C_{\mu}$ value) due to the pulsation or the reduced orifice area (segmented slot, sweeping jets) but also to 3D effects (counter-rotating streamwise vortices) or flow instability excitation (pulsed blowing slot) without the possibility to separate these different effects. In the pulsed blowing case, the highest lift increment was obtained for a forcing frequency close to the natural vortex shedding one. Since the sweeping jets have exhibited a good compromise between simplicity and mass flow rate reduction for a given lift increment, they have been selected for the second wind tunnel test.

In this test, flow separation control by sweeping jets on the rudder of a vertical tail plane was investigated. Side force increments up to $80 \%$ were achieved with a $2 \% C_{\mu}$ coefficient. It is also possible to reach side force increments of $50 \%$ with a lower $C_{\mu}$ value of $0.5 \%$ which represents only $0.2 \%$ of the mass flow of a single engine of a business jet during take-off. As already observed in the first wind tunnel test, the higher the freestream velocity, the higher the side force increment with sweeping jets. It was found that, with this type of actuation, the use of the mass flow coefficient $C_{Q}$ improves the agreement on the side force increment curves compared to the classical $C_{\mu}$ coefficient. A significant drag reduction (-26\% at $\left.C_{y}=0.5\right)$ was also observed which is an interesting result since the vertical tail plane area is determined by the eventuality of losing an engine during takeoff conditions. The investigation of larger actuator spacings enabled a reduction of the mass flow rate required to reach the same lift increment but, like in the first wind tunnel test, this gain comes with the drawback of a higher power coefficient $C_{\pi}$. The analysis of the first Aerodynamic Figure of Merit AFM1 has shown that it is possible to reach values higher than one for normally loaded vertical tail planes and low $C_{\mu}$ values or for highly loaded tails with large $C_{\mu}$ values. More generally speaking, to reach a $C_{\mu}$ objective (to suppress flow separation), it is interesting to decrease the actuator orifice area (segmented slot, sweeping jets) to increase the blowing velocity $U_{j}$ and consequently to decrease the required mass flow rate and the $C_{Q}$ value. On the other hand, to decrease the $C_{\pi}$ value, it is the opposite: it is interesting to increase the actuator orifice area to decrease $U_{j}$ which leads to an increase mass flow rate. From a power consumption point of view, it is more interesting to blow at low velocity on large areas but with the drawback of large mass flow rate values. This shows that a compromise has to be found between low mass flow rate ( $C_{Q}$ value) and low power consumption $\left(C_{\pi}\right.$ value). 


\section{Acknowledgments}

The model design and manufacturing was supported by the French Ministry of Defense. Part of this work was funded by ELSAT2020, a project co-financed by the European Union with the European Regional Development Fund, the French state and the Hauts-de-France Region Council. The authors would like to thank: Pierre Moré, Annabelle Lorenski and Emmanuel Eglinger for the model design and manufacturing and Murielle Lamoureux for the wind tunnel tests.

\section{References}

[1] Laban, M., Smaili, M. H., van der Heul, D. R., Arendsen, P., and Noordman, B. A. T., “Optimising High-Efficiency Rudders for Transport Aircraft Fuel Burn Reduction,” 26th International Congress of the Aeronautical Sciences (ICAS), Anchorage, Alaska, USA, 14 - 19 September 2008.

[2] Mooney, H. P., Brandt, J. B., Lacy, D. S., and Whalen, E. A., “AFC-Enabled Vertical Tail System Integration Study,” NASA CR-2014-218168, 2014.

[3] Gregory, J. W. and Tomac, M., “A Review of Fluidic Oscillator Development and Application for Control,” AIAA Paper 2013-2474, 43rd Fluid Dynamics Conference, San Diego, CA, 24-27 June 2013. doi: 10.2514/6.2013-2474

[4] Raman, G. and Raghu, S., “Cavity Resonance Suppression Using Miniature Fluidic Oscillators,” AIAA Journal, Vol. 42, No. 12, December 2004, pp. 2608-2611.

[5] Woszidlo, R., Nawroth, H., Raghu, S., and Wygnanski, I. J., “Parametric Study of Sweeping Jet Actuators for Separation Control,” AIAA Paper 2010-4247, 5th Flow Control Conference, 28 June - 1 July 2010, Chicago, Illinois. doi: 10.2514/6.20104247

[6] Woszidlo, R., and Wygnanski, I., “Parameters Governing Separation Control with Sweeping Jet Actuators,” AIAA Paper 2011-3172, 29th AIAA Applied Aerodynamics Conference, 27 - 30 June 2011, Honolulu, Hawaii. doi: 10.2514/6.2011-3172

[7] Pack Melton, L., “Active Flow Separation Control on a NACA 0015 Wing using Fluidic Actuators,” AIAA Paper 2014-2364, 7th AIAA Flow Control Conference, 16-20 June 2014, Atlanta, GA. doi: 10.2514/6.2014-2364

[8] Pack Melton, L., Koklu, M., “Active Flow Control using Sweeping Jet Actuators on a Semi-span Wing Model,” AIAA Paper 2016-1817, 54th AIAA Aerospace Sciences Meeting, San Diego, California, 4-8 January 2016. doi: 10.2514/6.2016-1817

[9] Pack Melton, L., Koklu, M., Andino, M., Lin, J. C., and Edelman, L., “Sweeping Jet Optimization Studies,” AIAA Paper 2016-4233, 8th AIAA Flow Control Conference, Washington, D.C., 13-17 June 2016. doi: 10.2514/6.2016-4233 
[10]Pack Melton, L., Koklu, M., Andino, M., Lin, J. C., and Shellabarger, E., “Active Flow Control for Trailing Edge Flap Separation,” AIAA Paper 2018-1799, AIAA Aerospace Sciences Meeting, Kissimmee, Florida, 8-12 January 2018. doi: doi: $10.2514 / 6.2018-1799$

[11]Pack Melton, L., Koklu, M., Andino, M., and Lin, J. C., “Active Flow Control via Discrete Sweeping and Steady Jets on a Simple-Hinged Flap,” AIAA Journal, Vol. 56, No. 8, pp. 2961-2973, 2018. doi: 10.2514/1.J056841

[12]Seele, R., Graff, E., Gharib, M., Taubert, L., Lin, J., and Wygnanski, I., “Improving Rudder Effectiveness with Sweeping Jet Actuators,” AIAA Paper 2012-3244, 6th AIAA Flow Control Conference, 25 - 28 June 2012, New Orleans, Louisiana. doi: $10.2514 / 6.2012-3244$

[13] Seele, R., Graff, E., Lin, J., and Wygnanski, I., "Performance Enhancement of a Vertical Tail Model with Sweeping Jet Actuators,” AIAA Paper 2013-0411, 51st AIAA Aerospace Sciences Meeting including the New Horizons Forum and Aerospace Exposition, 07 - 10 January 2013, Grapevine (Dallas/Ft. Worth Region), Texas. doi: 10.2514/6.2013-0411

[14] Lin, J. C., Andino, M. Y., Alexander, M. G., Whalen, E. A., Spoor, M. A., Tran, J. T. and Wygnanski, I. J. “An Overview of Active Flow Control Enhanced Vertical Tail Technology Development,” AIAA Paper 2016-0056, 54th AIAA Aerospace Sciences Meeting, San Diego, California, 4-8 January 2016. doi: 10.2514/6.2016-0056

[15] Whalen, E. A., Shmilovich, A., Spoor, M., Tran, J., Vijgen, P., Lin, J. C., and Andino, M., “Flight Test of an AFC Enhanced Vertical Tail,” AIAA Journal, Vol. 56, No. 9, pp. 3393-3398, 2018. doi: 10.2514/1.J056959

[16] Andino, M. Y., Lin, J. C., Seele, R., Graff, E. C., Gharib, M., Whalen, E. A., and Wygnanski, I. J., “Active Flow Control on Vertical Tail Models,” AIAA Journal, Vol. 57, No. 8, pp. 3322-3338, 2019. doi: 10.2514/1.J057876

[17] Lin, J. C., Whalen, E. A., Andino, M. Y., Graff, E. C., Lacy, D. S., Washburn, A. E., Gharib, M., and Wygnanski, I. J., “Full-Scale Testing of Active Flow Control Applied to a Vertical Tail,” Journal of Aircraft, Vol. 56, No. 4, pp. 1376-1386, 2019. doi: 10.2514/1.C034907

[18] Childs, R. E., Stremel, P. M., Garcia, J. A., Heineck, J. T., Kushner, L. K., and Storms, B. L., "Simulation of Sweep-Jet Flow Control, Single Jet and Full Vertical Tail,” AIAA Paper 2016-0569, 54th AIAA Aerospace Sciences Meeting, San Diego, California, 4-8 January 2016. doi: 10.2514/6.2016-0569

[19] Shmilovich, A., Yadlin, Y., and Whalen, E. A., "Numerical Simulations of an Airplane with an Active Flow Control System,” AIAA Paper 2016-3929, 8th AIAA Flow Control Conference, Washington, D.C., 13-17 June 2016. doi: $10.2514 / 6.2016-3929$

[20] Vatsa, V. N., Duda, B., and Lin, J. C., "Numerical Simulation of a High-Lift Configuration Embedded with High Momentum Fluidic Actuators,” AIAA Paper 2016-3932, 8th AIAA Flow Control Conference, Washington, D.C., 13-17 June 2016. doi: 10.2514/6.2016-3932 
[21] Shmilovich, A., Whalen, E. A., “A Technique for Low Input Flow Control Actuation,” AIAA Paper 2017-3040, 35th AIAA Applied Aerodynamics Conference, Denver, Colorado, 5-9 June 2017. doi: 10.2514/6.2017-3040

[22] Rathay, N. W., Amitay, M., and Whalen, E., "Flow Physics Associated with the Performance Enhancement of a Vertical Tail using Synthetic Jet Actuators,” AIAA Paper 2013-2797, 31st AIAA Applied Aerodynamics Conference, San Diego, CA, 2427 June 2013. doi: 10.2514/6.2013-2797

[23] Rathay, N. W., Boucher, M. J., Amitay, M., and Whalen, E., "Performance Enhancement of a Vertical Stabilizer using Synthetic Jet Actuators,” AIAA Journal, Vol. 52, No. 4, 2014. doi: 10.2514/1.J052645

[24] Rathay, N. W., Boucher, M. J., Amitay, M., and Whalen, E., "Parametric Study of Synthetic-Jet-Based Control for Performance Enhancement of a Vertical Tail,” AIAA Journal, Vol. 52, No. 11, 2014. doi: 10.2514/1.J052887

[25] Jansen, K. E., Rasquin, M., Farnsworth, J. A., Rathay, N., Monastero, M. C., and Amitay, M., "Interaction of a Synthetic Jet with Separated Flow over a Vertical Tail,” AIAA Journal, Vol. 56, No. 7, pp. 2653-2668, 2018. doi: 10.2514/1.J056751

[26] Shmilovich, A., Yadlin, Y., and Whalen, E. A., “Computational Evaluation of Flow Control for Enhanced Control Authority of a Vertical Tail,” AIAA Journal, Vol. 54, No. 8, pp. 2211-2220, 2016.

[27] Tewes, P., Taubert, L., and Wygnanski, I., “On the Effect of Sweep on Separation Control,” AIAA Paper 2014-2513, 7th AIAA Flow Control Conference, 16-20 June 2014, Atlanta, GA. doi: 10.2514/6.2014-2513

[28] Löffler, S., Staats, M., Grund, T., and J. Weiss, “Increasing the Effectiveness of a Vertical Stabilizer by Combining Pulsed Jet Actuation at the Leading Edge and the Rudder Hinge Line,” AIAA Paper 2018-2854, 2018 Applied Aerodynamics Conference, Atlanta, Georgia, 25-29 June 2018. doi: 10.2514/6.2018-2854

[29] Staats, M., Löffler, S., Ebert, C., Grund, T., and J. Weiss, “A Fluidic Device for Active Flow Control: Simulation vs. Experiment with Emphasis on Application,” AIAA Paper 2018-3336, 2018 Applied Aerodynamics Conference, Atlanta, Georgia, 25-29 June 2018. doi: 10.2514/6.2018-3336

[30] Löffler, S., Rohlfs, L., Staats, M., and Weiss, J., “Flow Field Investigation on a Vertical Stabilizer with Pulsed Jet Actuation by means of PIV Measurements,” AIAA Paper 2019-3499, AIAA Aviation 2019 Forum, Dallas, Texas, 17-21 June 2019. doi: $10.2514 / 6.2019-3499$

[31] Kröhnert, A., "Numerical Investigation of Tangential Blowing at the Rudder of a Vertical Tailplane Airfoil,” AIAA Paper 2014-2143, 32nd AIAA Applied Aerodynamics Conference, 16-20 June 2014, Atlanta, GA. doi: 10.2514/6.2014-2143

[32] Gebhardt, A., "Numerical Investigation of Unsteady Blowing Through Discrete Slots on a Swept Vertical Tail of Infinite Span,” AIAA Paper 2017-3244, 35th AIAA Applied Aerodynamics Conference, 5-9 June 2017, Denver, Colorado, doi: 10.2514/6.2017-3244

[33] Singh, V. M., Scholz, P., “Comparison of Different Vortex Generating Devices for Flow Control on a Vertical Tail,” AIAA Paper 2018-4023, 2018 Applied Aerodynamics Conference, Atlanta, Georgia, 25-29 June 2018. doi: 10.2514/6.2018-4023 
[34] Chabert, T., Dandois, J., Garnier, E., and Jacquin, L., “Experimental Detection of a Periodically Forced Turbulent Boundary Layer Separation,” Experiments in Fluids, Vol. 54, No. 2, pp. 1-14, 2013. doi: 10.1007/s00348-012-1430-1

[35] Chabert, T., Dandois, J., Garnier, E., and Jacquin, L., "Experimental detection of flow separation over a plain flap by wall shear stress analysis with and without steady blowing,” Comptes Rendus de l'Académie des Sciences, Vol. 342, n 6-7, pp. 389402, 2014. doi: 10.1016/j.crme.2014.01.013

[36] Chabert, T., Dandois, J., and Garnier, E., “Experimental closed-loop control of flow separation over a plain flap using slope seeking,” Experiments in Fluids, Vol. 55, No. 8, pp. 1-19, 2014. doi: 10.1007/s00348-014-1797-2

[37] Chabert, T., Dandois, J., and Garnier, E., “Experimental closed-loop control of separated-flow over a plain flap using extremum seeking,” Experiments in Fluids, Vol. 57, No. 3, pp. 1-17, 2016. doi: 10.1007/s00348-016-2123-y

[38] Poisson-Quinton, P., “Recherches théoriques et expérimentales sur le contrôle de couches limites,” Congress of Applied Mechanics, London, 1948.

[39] Poisson-Quinton, P. and Lepage, L., "Survey of French Research on the Control of Boundary Layer and Circulation," Lachmann G. (ed.), Boundary Layer and Flow Control, vol. 1, pp. 21-73, Pergamon, 1961.

[40] Greenblatt, D., and Wygnanski, I., “The control of flow separation by periodic excitation,” Prog. Aerospace Sci., Vol. 36, No 7, pp. 487-545, 2000. doi: 10.1016/S0376-0421(00)00008-7

[41] Seifert, A., “Closed-loop active flow control systems: Actuators”. In Active Flow Control; King, R., Ed.; Notes on Numerical Fluid Mechanics and Multidisciplinary Design; Springer: Berlin, Germany, Volume 95, pp. 85-102, 2007. 